\title{
Three Years Community-Based Intervention Program to Prevent Non-communicable Disease Risk Factors in Sousse, Tunisia
}

\author{
Nawel Zammit ${ }^{1}$, Jihene Maatoug ${ }^{1}$, Sana Bhiri ${ }^{1}$, Zineb Msakni ${ }^{1}$, Imed Harrabi ${ }^{1}$, Larbi Chaieb ${ }^{1}$, Habib Gamra $^{2}$ and \\ Hassen Ghannem ${ }^{1}$ \\ 1. Department of Epidemiology, University Hospital Farhat Hached, Sousse 4000, Tunisia \\ 2. Department of Cardiology, University Hospital Fattouma Bourguiba, Monastir 5000, Tunisia
}

Received: January 28, 2015 / Accepted: February 28, 2015 / Published: February 28, 2015.

\begin{abstract}
Aim: To evaluate the effectiveness of a community-based intervention program for NCD (non-communicable disease) risk factors prevention. Materials and methods: The authors conducted a quasi experimental study with a control group over five years between 2009 and 2014 in the region of Sousse, Tunisia. In each group, the sample size required was 1,000 participants. For this, the authors randomly selected 500 households from two areas and they included all adults aged 18 years and older in these households. They evaluated the habits of participants from both intervention and control groups at baseline in 2009-2010 and after three years of intervention in 2013-2014. They focused on the main lifestyle risk factors represented by poor diet, physical inactivity, and tobacco use. Results: Tobacco use decreased significantly among men by $7.3 \%(p=0.03)$ in the intervention group, versus an increase of $3.5 \%$ in the control group $(p=0.4)$. Physical activity and fruits and vegetables intake increased significantly respectively by $25 \%(p<0.001)$ and $19 \%(p<0.001)$ in intervention group. Conclusion: The results suggest that a combined community-based lifestyle intervention in a developing country, can significantly improve some NCD risk factors. However, a supportive environment or a gender approach is required to maximize the effectiveness and maintain the sustainability of the health intervention.
\end{abstract}

Keys words: Prevention, non-communicable disease, intervention, effectiveness, community.

\section{Introduction}

A global health transition is currently underway: NCDs (non-communicable diseases) became the leading cause of mortality worldwide [1]. More than $80 \%$ of the global NCD deaths occur in low- and middle income countries [2]. Between $70 \%$ and $90 \%$ of these deaths are believed to be caused by preventable lifestyle factors including tobacco use, poor diet, and physical inactivity [3, 4]. Reducing the NCD burden via lifestyle modification has, therefore, become an urgent public health priority [5]. It has been suggested that structured integrated programs are most effective

Corresponding author: Jihene Maatoug, Dr., research field: non-communicable disease prevention. E-mail: jihenmaatoug3107@gmail.com. in NCD prevention [6]. However, it is difficult to implement them in low and middle income countries where capacity is low and political systems are poorly responsive [6].

Interventions focusing on the whole community are attractive in terms of cost-effectiveness [7], as well as combined interventions which are more beneficial than sole dietary or physical activity interventions [7]. Tunisia, a developing country, also has to fight against the burden of the epidemiological transition. In this context, the purpose of the present study was to evaluate the short term effectiveness of a three year community-based intervention for NCD risk factors prevention in the region of Sousse. 


\section{Materials and Methods}

\subsection{Study Design}

The authors carried out between 2009 and 2014, in the region of Sousse, the "Together in Health" program: a quasi-experimental study with control group. The program targeted to reduce the main NCD risk factors such as poor diet, physical inactivity, and tobacco use in different settings: neighborhood, schools, and workplaces. In the paper, the authors report data about adults in neighborhood.

The first community which served as the intervention group was from the delegations of Sousse-Jawhara and Sousse-Erriadh. The control group was from the delegation of Msaken located 12 kilometers away from the region of Sousse. The authors evaluated the habits of participants from both groups at baseline in 2009-2010. The authors focused on lifestyle risk factors represented by poor diet, physical inactivity, and tobacco use. Then an intervention was undertaken during three years in the intervention area. A second evaluation of the same habits was conducted after the intervention in both groups in 2013-2014.

\subsection{Studied Population}

Sample size calculation was based on a significance level of $\alpha=5 \%$, power of test $\beta=20 \%$, two-sided test of hypothesis and $6 \%$ change in risk factors levels (tobacco use, poor diet and physical inactivity) giving a total sample of 1,000 adults in each group.

The authors used cluster sampling to select 1,000 households (500 households from each area) from 16 randomly selected districts. The authors included all adults aged 18 years and older in these households.

The baseline and post intervention evaluations were collected from two independent samples in each group.

\subsection{Data Collection}

The authors used, a questionnaire developed by the Oxford Health Alliance for the Community Interventions for Health project to collect data among participants in both groups. The authors translated this questionnaire to Arabic and pre-tested it before use. Pre-trained interviewers ensured the standardized administration at baseline and post intervention. The questionnaire enabled the authors to collect data about: self-reported socio-demographic characteristics, tobacco use, eating habits, and physical activity habits.

\subsection{Variables Definitions}

To define smokers among adults: the authors asked participants, "Do you currently smoke any tobacco products, such as cigarettes, cigars, or pipes?" Smokers were the participants who responded yes to this question.

The recommended level of physical activity was used as defined by the WHO (World Health Organization) for adults: $150 \mathrm{~min}$ of moderate-intensity aerobic physical activity throughout the week or at least $75 \mathrm{~min}$ of vigorous-intensity aerobic physical activity throughout the week or an equivalent combination [8].

The daily consumption of at least five serving of fruits and vegetables was used to assess eating habits.

\subsection{Intervention Program}

During the three years between September 2010 and September 2013, community members in the intervention area were targeted in different settings.

In fact, they were periodically invited to participate in open days organized by the authors' team of medical doctors. There was a screening of overweight, diabetes and hypertension as well as sensitization about the three topics: tobacco cessation, healthy diet and physical activity. In addition, leaflets about the three topics were distributed to their houses. Moreover, the authors organized broadcasts and repetitive short messages about NCDs prevention through local radio stations.

This community-based intervention was enhanced, not only by two similar intervention programs in schools and workplaces, but also by a training of primary care physicians about NCDs management and 
prevention.

The control group did not receive any kind of intervention from the authors' team during the three years. Nevertheless, in January 2011, a sociopolitical revolution came up in Tunisia which limited their possibilities to lead environmental actions and structural changes.

\subsection{Data Analyses}

Statistical analysis was performed using the SPSS 10.0 software. The authors used chi-square test to compare percentages and student's $t$-test to compare means in independent groups with 0.05 as significance level.

\subsection{Ethical Considerations}

Protocol, data collection forms, questionnaires and the manual of investigation methods were approved by the Ethic Committee of Farhat Hached University Hospital of Sousse. In addition to that, the authors asked also for authorizations from the Ministry of Health and the governor of the city of Sousse. Furthermore, they obtained an informed consent from each participant before the interview.

\section{Results}

\subsection{Response Rate}

At baseline, the authors' study population consisted of 940 adults in each group with a global response rate of $73.3 \%$. At post intervention, they obtained 1,001 participants in the intervention group and 976 in control group. The global response rate was $68 \%$.

\subsection{Socio-Demographic Characteristics}

Women represented $56.8 \%$ of participants at baseline and $55.8 \%$ at post intervention $(p=0.67)$ in the intervention group. They represented respectively $71.2 \%$ and $65.7 \%$ of participants at baseline and post intervention in the control group ( $p=0.01)$.

Participants had a mean age of $37.2 \pm 13.2$ years at baseline in intervention group, it was about $39.2 \pm 13.6$ years at post intervention $(p=0.001)$. For the control group it was $38.6 \pm 13.7$ years at baseline and $40.4 \pm$ 13.9 years at post intervention $(p=0.004)$.

In the intervention group, participants with low to middle socioeconomic status represented $62.8 \%$ at baseline and $58.3 \%$ at post intervention ( $p=0.04$ ). In control group they represented $65.2 \%$ at baseline and $54.8 \%$ at post intervention $(p<0.001)$.

\subsection{Habits Evaluation}

\subsubsection{Tobacco Use}

The tobacco use decreased insignificantly in the intervention group from $26.2 \%$ to $23.2 \%(p=0.1)$. While, it increased significantly in the control group from $14.4 \%$ to $18.3 \%(p=0.02)$.

Adjusting by sex, revealed a significant decrease among men in intervention group from $52.9 \%$ to $45.6 \%$ $(p=0.03)$ versus an insignificant increase in control group from $46.9 \%$ to $50.4 \%$ ( $p=0.4)$. With women there was no significant change (Table 1). For the two age categories under and over 40 years, there was insignificant decrease in tobacco use within intervention group and increase in control group (Table 1).

Tobacco use decreased among participants in the higher socioeconomic level by $4.7 \%$ in the intervention group ( $p=0.1$ ) versus no significant change in the control group $(p=0.9)$. While among those in the lower socioeconomic level, tobacco use decreased by $1.4 \%(p=0.6)$ in intervention group and increased by $5.4 \%$ in control group $(p=0.009)$ (Table 1$)$.

\subsubsection{Physical Activity}

Concerning the practice of the recommended level of physical activity, we observed significant improvement in intervention group from $15.1 \%$ to $40.1 \%(p<0.001)$ and from $15 \%$ to $38.5 \%$ in control group $(p<0.001)$. The authors observed in intervention group, much more improvement with men $(26.3 \%)$ than women $(8.2 \%)(p<0.001)$ and with people older than 40 years $(29.5 \%)$ than those younger $(21.9 \%)(p<0.001)$. However, in the control group the improvement was higher with women and the youngest people (Table 2). 
Table 1 Tobacco use at baseline and post intervention in intervention and control groups among the different categories of participants.

\begin{tabular}{|c|c|c|c|c|c|c|}
\hline \multirow[b]{2}{*}{ Sex } & \multicolumn{3}{|c|}{ Intervention group } & \multicolumn{3}{|c|}{ Control group } \\
\hline & Baseline & $\begin{array}{l}\text { Post } \\
\text { intervention }\end{array}$ & $p$-value & Baseline & $\begin{array}{l}\text { Post } \\
\text { intervention }\end{array}$ & $p$-value \\
\hline Men n (\%) & $213(52.9)$ & $201(45.6)$ & 0.03 & $127(46.9)$ & $169(50.4)$ & 0.4 \\
\hline Women n (\%) & $29(5.6)$ & $31(5.5)$ & 0.1 & $8(1.2)$ & $9(1.4)$ & 0.7 \\
\hline \multicolumn{7}{|l|}{ Age } \\
\hline$\leq 40$ years $\mathrm{n}(\%)$ & $133(24.9)$ & $122(22.8)$ & 0.4 & $82(15.4)$ & $97(19.6)$ & 0.07 \\
\hline$>40$ years $n(\%)$ & $106(27.6)$ & $110(23.7)$ & 0.2 & $52(12.9)$ & $81(16.9)$ & 0.09 \\
\hline \multicolumn{7}{|l|}{ Socioeconomic level } \\
\hline Low \& middle n (\%) & $154(26.6)$ & $146(25.2)$ & 0.6 & $71(11.6)$ & $91(17.0)$ & 0.009 \\
\hline Middle \& High n (\%) & $87(25.4)$ & $86(20.7)$ & 0.1 & $64(19.6)$ & $87(19.8)$ & 0.9 \\
\hline
\end{tabular}

Table 2 Practice of the recommended physical activity at baseline and post intervention in intervention and control groups among the different categories of participants.

\begin{tabular}{|c|c|c|c|c|c|c|}
\hline \multirow[b]{2}{*}{ Sex } & \multicolumn{3}{|c|}{ Intervention group } & \multicolumn{3}{|c|}{ Control group } \\
\hline & Baseline & $\begin{array}{l}\text { Post } \\
\text { intervention }\end{array}$ & $p$-value & Baseline & $\begin{array}{l}\text { Post } \\
\text { intervention }\end{array}$ & $p$-value \\
\hline Men n (\%) & $73(18.1)$ & $195(44.4)$ & $<0.001$ & $62(22.9)$ & $145(43.4)$ & $<0.001$ \\
\hline Women n (\%) & $57(18.1)$ & $99(26.3)$ & $<0.001$ & $79(11.8)$ & $230(36.0)$ & $<0.001$ \\
\hline \multicolumn{7}{|l|}{ Age } \\
\hline$\leq 40$ years $\mathrm{n}(\%)$ & $93(17.2)$ & $209(39.1)$ & $<0.001$ & $76(14.3)$ & $200(40.6)$ & $<0.001$ \\
\hline$>40$ years $n(\%)$ & $46(11.8)$ & $191(41.3)$ & $<0.001$ & $64(15.9)$ & $175(36.7)$ & $<0.001$ \\
\hline \multicolumn{7}{|l|}{ Socioeconomic level } \\
\hline Low \& middle n (\%) & $312(53.0)$ & $334(57.5)$ & 0.1 & $319(52.0)$ & $327(61.1)$ & 0.002 \\
\hline Middle \& High n (\%) & $183(52.4)$ & $213(51.2)$ & 0.7 & $188(57.5)$ & $261(59.2)$ & 0.6 \\
\hline
\end{tabular}

While in both the intervention and control groups, participants in the lower socioeconomic level increased their physical activity more than those in the higher socioeconomic level (Table 2).

\subsubsection{Dietary Habits}

The daily consumption of five servings of fruits and vegetables increased significantly from $39.4 \%$ to $58.4 \%$ $(p<0.001)$ in the intervention group and from $51.4 \%$ to $67.9 \%(p<0.001)$ in control group. When adjusted by sex, age, and socioeconomic level, the authors found also a significant increase with all categories in both groups (Table 3). Moreover, salty food intake decreased significantly respectively by $5.5 \%$ and by $10 \%$ in both the intervention $(p=0.01)$ and control groups $(p<0.001)$. Snack intake also decreased in both groups, but these decreases were not significant

\section{Discussion}

The authors' study showed an improvement on some
NCD risk factors similar to those of the other community-based interventions in developing countries [9].

The authors succeeded in reducing tobacco use especially among men. However, they observed no effect among women. This anti smoking effect was more pronounced within men than women was also seen in other developing country interventions such as those described in a large-scale study in Singapore [10] and Iran [11]. It has been suggested that there are some differences in the reasons for smoking cessation attempts by sex, which shows the necessity for interventions designed specifically for women [12]. The authors also observed a limited decrease in tobacco use among people from the low socioeconomic level. A slower decline in tobacco use within persons of lower socioeconomic status is frequently reported [13-18]. Indeed they have more difficulties in quitting tobacco for several reasons, including more limited 
Table 3 Consumption of 5 serving of fruits and vegetables at baseline and post intervention in intervention and control groups among the different categories of participants.

\begin{tabular}{|c|c|c|c|c|c|c|}
\hline \multirow[b]{2}{*}{ Sex } & \multicolumn{3}{|c|}{ Intervention group } & \multicolumn{3}{|c|}{ Control group } \\
\hline & Baseline & $\begin{array}{l}\text { Post } \\
\text { intervention }\end{array}$ & $p$-value & Baseline & $\begin{array}{l}\text { Post } \\
\text { intervention }\end{array}$ & $p$-value \\
\hline Men n (\%) & $161(39.8)$ & $244(55.6)$ & $<0.001$ & $122(45.0)$ & $234(69.9)$ & $<0.001$ \\
\hline Women n (\%) & $207(39.1)$ & $235(60.6)$ & $<0.001$ & $361(54.0)$ & 429 (66.9) & $<0.001$ \\
\hline \multicolumn{7}{|l|}{ Age } \\
\hline$\leq 40$ years $\mathrm{n}(\%)$ & $202(37.5)$ & $257(51.6)$ & $<0.001$ & $272(51.0)$ & 317 (64.2) & $<0.001$ \\
\hline$>40$ years $\mathrm{n}(\%)$ & $162(41.6)$ & $304(66.2)$ & $<0.001$ & 209 (51.9) & $343(71.6)$ & $<0.001$ \\
\hline \multicolumn{7}{|l|}{ Socioeconomic level } \\
\hline Low \& middle $n(\%)$ & $169(28.8)$ & $249(43.2)$ & $<0.001$ & $281(46.0)$ & $370(69.4)$ & $<0.001$ \\
\hline Middle \& High n (\%) & $136(39.2)$ & $250(60.5)$ & $<0.001$ & $181(55.7)$ & $308(70.0)$ & $<0.001$ \\
\hline
\end{tabular}

access to treatment, misinformation, lack of social support, discrimination, and other life stressors [13-18].

Existing evidence suggests that tobacco use prevention, delivered in combination with other health services, might be a more effective approach [19]. In the intervention, the authors targeted physical activity and dietary habits along with the tobacco cessation.

Concerning physical activity, they observed in the intervention group much more improvement among men than women, with people older than 40 years than those younger and with those from lower socioeconomic levels than those from higher socioeconomic levels. Studies conducted in developed and developing countries have shown that men are more physically active than women [20-22].

These findings seem to be related to a lack of motivation and free time, and special attitudes in women [21, 22].

Other researchers have detected a strong inverse association between age and physical activity [23, 24] related perhaps to a lack of discretionary time, increasing work time, and family responsibilities that commonly occur during the life course. However, in the study, the recommended physical activity increased among older people in the intervention group. This result is similar with a study reported by Del Duca G et al. [25] where they detected a positive association between age and walking besides a negatively association with soccer and weight lifting.
As shown in several other studies, the authors' findings showed that with the lower socioeconomic status level they have a higher rate of physical activity [26-29]. In the same context, Droomers et al. found among low socioeconomic status groups: lower leisure-time and more occupational physical activity [30].

In regard to dietary habits, the authors' intervention had a positive effect on some of them. Fruits and vegetables consumption increased among all the community categories. Like many Mediterranean countries, in Tunisia fruits and vegetables are relatively accessible to people from the different socioeconomic levels. Moreover, salty foods as well as snack intake decreased in intervention group. Similar outcomes in five comprehensive community-based interventions were reported by a systemic review where there was an increase of the frequency of healthful food intake [31].

Limited effects with sex, age, and socioeconomic status highlighted the importance of culture, age, and sex-specific interventions.

Some improvements in intervention group related to dietary habits and physical activity were also seen in the control group. Diffusion effects may explain this result. In fact, the delegation of Msaken is 12 kilometers away from the city of Sousse where the authors organized open days. Moreover, they provided interventions through the local radio station which could be heard in the both areas. A reaction of people to the baseline survey "Hawthorne effect" may have also 
happened in control group: participants could improve their behavior after being interviewed because of their awareness that they will be observed.

The community-based intervention was concomitant with two similar interventions: one in workplaces and another in schools. Nevertheless their intervention might be more effective if the authors could apply some environmental changes. Unfortunately, the programmed structural and environmental actions were not applied in our study; this was due to the political instability that happened in Tunisia since January 2011. While, it is known that comprehensive strategies are the most effective interventions in preventing NCDs [32-36].

\subsection{Strength and Limitation}

The study is considered between the rare community-based interventions in Tunisia with a large sample. The choice of intervention and control areas took into consideration an adequate distance between the two groups to avoid contamination but at the same time it should not be very far to ensure the feasibility of data collection. The intervention lasted three years, the authors have few other studies having such important period before in Tunisia but this period could be considered limited compared to other international studies. Self assessment of habits by participants could be a source of error especially when measuring small behavior changes.

Across the intervention, the authors have seen a political instability: the "Tunisian revolution" that is why they had to double efforts to imply the new responsibilities and adapt our program with the new social conditions. Therefore, multi-sectorial and structural actions were limited in our program because decision makers had other priorities and challenges after this revolution.

\section{Conclusion}

Combined community-based lifestyle intervention in a developing country can significantly improve some NCD risk factors over a relatively short time span. Some limited effects linked to particular characteristics suggested that a supportive environment or a gender approach, is required to maximize the effectiveness and maintains the sustainability of the health intervention.

\section{Acknowledgments}

The article was based on a project funded by the "United Health Group" and by the Research Unit "Santé UR 12SP28": Epidemiologic transition and prevention of chronic disease" of the Ministry of Higher Education, Tunisia.

\section{Competing interests}

The authors have no conflict of interest.

\section{References}

[1] Lopez, A. D., Mathers, C. D., Ezzati, M., Jamison, D. T., and Murray, C. J. L. 2006. "Global and Regional Burden of Disease and Risk Factors, 2001: Systematic Analysis of Population Health Data." Lancet. 367 (9524): 1747-57.

[2] WHO. 2010. "Global Status Report on Non-communicable Diseases.” WHO. Accessed April 24, 2015.

http://www.who.int/nmh/publications/ncd_report2010/en/

[3] WHO. 2002. "The World Health Report 2002-Reducing Risks, Promoting Healthy Life.” WHO. Accessed April 24, 2015. http://www.who.int/whr/2002/en/.

[4] WHO. 2008-2013. "Action Plan for the Global Strategy for the Prevention and Control of Non-communicable Diseases." WHO. Accessed April 24, 2015. http://www.who.int/nmh/publications/9789241597418/en /.

[5] Maher, D., Ford, N., and Unwin, N. 2012. "Priorities for Developing Countries in the Global Response to Non-communicable Diseases." Glob Health 11 (6): 8-14.

[6] Institute of Medicine (US) Committee on Preventing the Global Epidemic of Cardiovascular Disease: Meeting the Challenges in Developing Countries. 2010. Promoting Cardiovascular Health in the Developing World: A Critical Challenge to Achieve Global Health, edited by Fuster, V., Kelly, B. B. Washington, DC: National Academies Press (US). Accessed April 24, 2015. http://www.ncbi.nlm.nih.gov/books/NBK45693/.

[7] Saha, S., Gerdtham, U. G., and Johansson, P. 2010. "Economic Evaluation of Lifestyle Interventions for Preventing Diabetes and Cardiovascular Diseases." Int $J$ 
Environ Res Public Health 7 (8): 3150-95.

[8] WHO. "Global Recommendations on Physical ACTIVITY for health.” WHO. Accessed April 24, 2015. http://www.who.int/dietphysicalactivity/factsheet_recom mendations/en/.

[9] Van de Vijver, S., Oti, S., Addo, J., de Graft-Aikins, A., and Agyemang, C. "Review of Community-Based Interventions for Prevention of Cardiovascular Diseases in Low- and Middle-Income Countries." Ethn Health 17: (6) :651-76.

[10] Bhalla, V., Fong, C. W., Chew, S. K., and Satku, K. 2006. "Changes in the Levels of Major Cardiovascular Risk Factors in the Multi-ethnic Population in Singapore after 12 Years of a National Non-communicable Disease Intervention Programme." Singapore Med J. 47 (10): 841-50.

[11] Sarrafzadegan, N., Sadeghi, M., Tavassoli, A., Mohseni, M., Alikhasi, H., and Rabiei, K. et al. 2009. "Sex Differences in the Impact of a Community-Based Program for Non-Communicable Disease Prevention: The Isfahan Healthy Heart Program (IHHP).” J Public Health 17 (4): 257-63.

[12] Stewart, M. J., Brosky, G., Gillis, A., Jackson, S., Johnston, G., and Kirkland, S. et al. 1996. "Disadvantaged Women and Smoking." Can J. Public Health Rev. Can Santé Publique 87 (4): 257-60.

[13] Haas, J. S., Linder, J. A., Park, E. R., Gonzalez, I., Rigotti, N. A., and Klinger, E. V. et al. 2015. "Proactive Tobacco Cessation Outreach to Smokers of Low Socioeconomic Status: A Randomized Clinical Trial." JAMA Intern Med. 175 (2): 218-26.

[14] Browning, K. K., Ferketich, A. K., Salsberry, P. J., and Wewers, M. E. 2008. "Socioeconomic Disparity in Provider-Delivered Assistance to Quit Smoking." Nicotine Tob. Res. 10 (1): 55-61.

[15] Christiansen, B., Reeder, K., Hill, M., Baker, T. B., and Fiore, M. C. 2012. "Barriers to Effective Tobacco-Dependence Treatment for the Very Poor." $J$. Stud. Alcohol Drugs 73 (6): 874-84.

[16] Businelle, M. S., Kendzor, D. E., Reitzel, L. R., Costello, T. J., Cofta-Woerpel, L., and Li, Y. et al. 2010. "Mechanisms Linking Socioeconomic Status to Smoking Cessation: A Structural Equation Modeling Approach." Health Psychol Off J. Div. Health Psychol Am. Psychol Assoc. 29 (3): 262-73.

[17] Sheffer, C. E., Stitzer, M., Landes, R., Brackman, S. L., Munn, T., and Moore, P. 2012. "Socioeconomic Disparities in Community-Based Treatment of Tobacco Dependence." Am. J. Public Health 102 (3): e 8-16.

[18] Hiscock, R., Bauld, L., Amos, A., Fidler, J. A., and Munafò, M. 2012. "Socioeconomic Status and Smoking:
A Review." Ann N. Y. Acad Sci. 1248 (2): 107-23.

[19] Murray, R. L., Bauld, L., Hackshaw, L. E., and McNeill, A. 2009. "Improving Access to Smoking Cessation Services for Disadvantaged Groups: A Systematic Review." J. Public Health Oxf. Engl. 31 (2): 258-77.

[20] Talaei, M., Rabiei, K., Talaei, Z., Amiri, N., Zolfaghari, B., and Kabiri, P. 2013. "Physical Activity, Sex, and Socioeconomic Status: A Population Based Study." ARYA Atheroscler 9 (1): 51-60.

[21] Chinn, D. J., White, M., Harland, J., Drinkwater, C., and Raybould, S. 1999. "Barriers to Physical Activity and Socioeconomic Position: Implications for Health Promotion." J. Epidemiol Community Health 53 (3): 191-2.

[22] Azevedo, M. R., Araújo, C. L. P., Reichert, F. F., Siqueira, F. V., da Silva, M. C., and Hallal, P. C. 2007. "Gender Differences in Leisure-Time Physical Activity." Int. J. Public Health 52 (1): 8-15.

[23] DiPietro, L. 2001. "Physical Activity in Aging: Changes in Patterns and Their Relationship to Health and Function." J. Gerontol A Biol. Sci. Med. Sci. 56 (2): 13-22.

[24] Lachman, M. E. 2001. Handbook of Midlife Development. Accessed April 24, 2015. http://www.wiley.com/WileyCDA/WileyTitle/productCd $-047133331 X . h t m l$.

[25] Del Duca, G. F., Nahas, M. V., Hallal, P. C., and Peres, K. G. 2014. "Leisure-Time Physical Activities among Adults in Florianopolis, State of Santa Catarina, Brazil: A Population-Based Study on the Characteristics of the Practices and the Practitioners." Ciênc Saúde Coletiva 19 (11): 4595-604

[26] Iribarren, C., Luepker, R. V., McGovern, P. G., Arnett, D. K., and Blackburn, H. 1997. "Twelve-Year Trends in Cardiovascular Disease Risk Factors in the Minnesota Heart Survey. Are Socioeconomic Differences Widening?' Arch. Intern. Med. 157 (8): 873-81.

[27] Mensink, G. B., Loose, N., and Oomen, C. M. 1997. "Physical Activity and Its Association with Other Lifestyle Factors.” Eur. J. Epidemiol. 13 (7): 771-8.

[28] Wister, A. V. 1996. "The Effects of Socioeconomic Status on Exercise and Smoking: Age-Related Differences." $J$. Aging Health 8 (4): 467-88.

[29] McNeill, L. H., Kreuter, M. W., and Subramanian, S. V. 2006. "Social Environment and Physical Activity: A Review of Concepts and Evidence." Soc. Sci. Med. 63 (4): 1011-22.

[30] Droomers, M., Schrijvers, C. T., van de Mheen, H., and Mackenbach, J. P. 1998. "Educational Differences in Leisure-Time Physical Inactivity: A Descriptive and Explanatory Study.” Soc. Sci. Med. 47 (11): 1665-76.

[31] Gittelsohn, J., Lee-Kwan, S. H., and Batorsky, B. 2013. 
"Community-Based Interventions in Prepared-Food Sources: A Systematic Review." Prev. Chronic Dis. 10 (31). Accessed April 24, 2015. http://www.cdc.gov/pcd/issues/2013/13_0073.htm.

[32] Rose, G. 1981. "Strategy of Prevention: Lessons from Cardiovascular Disease.” Br. Med. J. Clin. Res. Ed. 282 (6279): 1847-51.

[33] HEART HEALTH EQUALITY MOBILIZING COMMUNITIES ACTION [1 fiche] - TERMIUM Plus ${ }^{\circledR}$ — Recherche - TERMIUM Plus ${ }^{\circledR}$. 2009. Accessed April 24 , 2015. http://www.btb.termiumplus.gc.ca/tpv2alpha/alpha-fra.ht ml?lang=fra\& $i=1 \&$ index $=$ alt $\&$ srcht $x t=H E A R T \% 20 H E A$ LTH\%20EQUALITY\%20MOBILIZING\%20COMMUN
ITIES\%20ACTION.

[34] Baker, E. A., and Brownson, C. A. 1998. "Defining Characteristics of Community-Based Health Promotion Programs." J. Public Health Manag Pract JPHMP. 4 (2): 1-9.

[35] Haggis, C., Sims-Gould, J., Winters, M., Gutteridge, K., McKay, H. A. 2013. "Sustained Impact of Community-Based Physical Activity Interventions: Key Elements for Success." BMC Public Health 13 (1): 892.

[36] Lachat, C., Otchere, S., Roberfroid, D., Abdulai, A., Seret, F. M. A., and Milesevic, J. et al. "Diet and Physical Activity for the Prevention of Noncommunicable Diseases in Low- and Middle-Income Countries: A Systematic Policy Review." PLoS Med. 10 (6): e1001465. 